\title{
La combinación amlodipina-perindopril fue más eficaz que atenolol-diurético para reducir los eventos mayores en hipertensos
}

\section{Objetivo}

Comparar la incidencia de eventos fatales y no fatales entre las combinaciones atenolol -tiazida vs. amlodipina -perindopril.

Diseño

Estudio multicéntrico, prospectivo, aleatorizado, controlado.

\section{Lugar}

Gran Bretaña y países nórdicos.

\section{Pacientes}

19.257 hipertensos no tratados o no controlados entre 40-79 años, en su mayoría hombres, con un riesgo cardiovascular moderado o alto ( 3 o más factores de riesgo). Se excluyeron pacientes con enfermedad coronaria, ACV, triglicéridos elevados, o historia de paro cardíaco, arritmias no controladas o alteraciones hematológicas.

\section{Intervención}

9639 pacientes fueron asignados a la rama amlodipina-perindopril y 9618 a la rama atenolol - diurético. El seguimiento promedio fue de 5,5 años.

El $78 \%$ de los pacientes requirió un promedio de 2,2 drogas para mantener su presión en cifras normales. En el caso de requerir una tercera droga se utilizó doxazocina a dosis habituales.

\section{Medición de Resultados Principales}

El punto final primario fue disminución de eventos totales (fatales y no fatales) y los secundarios, disminución de mortalidad total, mortalidad cardiovascular, ACV, eventos coronarios y procedimientos. Se midieron además incidencia de IAM silente, angina inestable, angina crónica estable, enfermedad arterial periférica, arritmias, desarrollo de diabetes y daño renal.

\section{Resultados principales}

El $99 \%$ de los pacientes continuaba en seguimiento al finalizar el estudio. Se realizó análisis por intención de tratar.

Los eventos totales se redujeron un 10\% a favor del grupo amlodipina-perindopril (diferencia no significativa) sin embargo la combinación perindopril-amlodipina disminuyó significativamente la mortalidad de causa cardiovascular (24\%) y total (13\%), el ACV (23\%), los eventos coronarios (13\%) y el desarrollo de diabetes (30\%). Ver Tabla 1. Las diferencias también fueron significativas en relación a angina inestable, enfermedad vascular periférica y daño renal. De acuerdo a estos resultados, en Octubre del 2004 el Comité evaluador recomendó concluir el estudio en forma prematura por las marcadas diferencias de resultados entre grupos.

\begin{tabular}{|c|c|c|c|c|c|}
\hline Resultados & \begin{tabular}{|c|c}
\multicolumn{1}{c}{ Eventos } \\
atenolol-tiazida \\
$\mathrm{n}=\mathbf{9 6 1 8}$
\end{tabular} & $\begin{array}{c}\text { Eventos } \\
\text { amlodipina- } \\
\text { perindopril } n=9639\end{array}$ & RR (LC 95\%) & NNT & $\mathbf{p}$ \\
\hline Primarios & 474 & 429 & $0,90(0,79-1,02)$ & - & NS \\
\hline Secundarios & 444 & 390 & $0,87(0,76-1,00)$ & 909 & 0,04 \\
\hline Desarrollo diabetes & 799 & 567 & $0,70(0,63-0,78)$ & 204 & $<0,0001$ \\
\hline Mortalidad total & 820 & 738 & $0,89(0,81-0,99)$ & 897 & 0,02 \\
\hline $\begin{array}{l}\text { Mortalidad } \\
\text { cadiovascular }\end{array}$ & 342 & 263 & $0,76(0,65-0,90)$ & 625 & 0,001 \\
\hline ACV totales & 422 & 327 & $0,77(0,66-0,89)$ & 526 & 0,0003 \\
\hline
\end{tabular}

$\mathrm{NS}=$ No significativa

\section{Conclusión}

La combinación amlodipina-perindopril fue más eficaz que atenololtiazidas en disminuír la mortalidad total y cardiovascular así como los eventos cerebro y cardiovasculares, la diabetes y el daño renal.

Fuente de Financiamiento: Laboratorio Pfizer.

\section{Comentario}

Resultan impactantes los resultados reportados tanto en la reducción de riesgos como en las curvas de sobrevida a favor del grupo amlodipina-perindopril. De los resultados se desprende que la combinación en cuestión no sólo previene eventos cardio y cerebrovasculares sino también reduce la mortalidad e induce menor desarrollo de diabetes y daño renal. Cabe destacar el cuidadoso diseño del estudio, con una gran cantidad de pacientes incluídos y escasísima pérdida de seguimiento. Sin embargo la forma de reportar los datos en riesgos relativos sobredimensiona el beneficio real de la combinación, ya que si se observan los NNT estos son bastante grandes y el beneficio, si bien existe, no es tan "contundente". Por otra parte, los resultados nos dicen que una combinación conlleva una disminución mayor de eventos, lo cual no significa que la alternativa no sea eficaz.

Estudios previos mostraron beneficios con las tiazidas ${ }^{1}$ y con los "sartanes"2, por lo que los bloqueantes beta podrían ser los responsables de la menor reducción de riesgo del grupo atenolol-tiazida. En el presente estudio se indicó atenolol a pacientes ancianos, lo cual no es hoy la práctica habitual. Con respecto a la posología, se comenzaba con $50 \mathrm{mg}$. y luego se incrementaba la dosis antes de agregar el diurético, práctica que tampoco es la habitualmente recomendada. Es probable que esto pueda haber contribuido a la menor eficacia relativa de la combinación que incluía el beta-bloqueante.Con las salvedades mencionadas previamente, este trabajo cambia la práctica en relación al uso de estas drogas, las que quedarían reservadas como primera línea sólo para los hipertensos coronarios.Aproximadamente un tercio de los pacientes en ambos grupos eran diabéticos conocidos, y el no haber tratado a un grupo con "priles" crea un dilema ético. El hecho de que se haya incluído un alto porcentaje de pacientes con hipertrofia ventricular izquierda conocida puede haber sobreestimado también el efecto de la combinación con priles. Por último, es importante recordar que los pacientes incluidos en este estudio eran hipertensos severos con dos o más factores de riesgo; población que no corresponde a la que habitualmente tratamos en el consultorio, y surge también el interrogante sobre cuántos de nuestros pacientes controlados actualmente con un esquema económico y eficaz como el atenolol diuréticos podrían pagar la combinación amlodipina -perindopril.

\section{Conclusiones de las comentadoras}

Este estudio aporta información importante, aunque los resultados absolutos no son tan contundentes como los relativos. Los NNT son grandes, el tratamiento es más costoso y el uso de beta-bloqueantes tal como fueron utilizados no representa la práctica recomendada actualmente. Como resumen para el consultorio ante un paciente hipertenso podríamos comenzar administrando un diurético, luego agregaríamos un IECA y en tercer lugar un bloqueante - cálcico. y si el paciente tiene un evento coronario incluiríamos un beta-bloqueante.

Marcela López, Noelia Capellato, Victoria Wurcel. [ Unidad Medicina Familiar y Preventiva. Hospital Italiano Buenos Aires. ]

López Marcela, Capellato Noelia, Wurcel Victoria.La combinación amblodipina-perindopril fue más eficaz que atenolol-diurético para reducir eventos mayores en hipertensos. Evid actual práct amb. 2005:8:133. Comentado de Dahlof B et al. Prevention of cardiovascular events with an antihypertensive regimen of amlodipine adding perindopril as required versus atenolol adding bendroflumethiazide as required, in the Anglo-Scandinavian Cardiac Outcomes Trial-Blood Pressure Lowering Arm (ASCOT-BPLA): a multicentre randomised controlled trial. Lancet. 2005 Sep 1016;366(9489):895-906. PMID: 16154016

\section{Referencias}

1. ALLHAT collaborative group. Major outcomes in high-risk hypertensive patients randomized to angiotensin-converting enzyme inhibitor or calcium channel blocker vs. diuretic: The Antihypertensive and Lipid-Lowering Treatment to Prevent Heart Attack Trial (ALLHAT).JAMA. 2002 Dec 18;288(23):2981-97. Erratum in: JAMA 2003 Jan 8; 289(2):178.JAMA. 2004 May 12; 291(18):2196. PMID: 12479763 2. Hanson $L$ et al. Effect of angiotensin - converting-enzyme inhibition compared with conventional therapy on cardiovascular morbidity and mortality in hypertension: the Captopril Prevention Project (CAPPP) randomised trial. Lancet. 1999 Feb 20; 353(9153):611-6. PMID: 10030325 